\title{
Measuring the economic impacts of recent oil price shocks on oil-dependent economy: evidence from Malaysia
}

\begin{abstract}
This paper examines the economy-wide impacts of recent oil price shocks on the Malaysian economy. To achieve this objective, an integrated methodological framework that combines econometric and input-output models is utilized to assess the impacts of an oil price shock on tax revenues, employment, labor income and gross domestic product (GDP). Our results reveal that the recent oil price shocks significantly affects these macroeconomic variables. The decline in oil prices from 2015 to 2016 reduces tax revenues by $10.5 \%$, lower GDP by $1.9 \%$ and increases the unemployment rate by $0.3 \%$. As such, the sharp crunch in oil prices serves as a reminder to policymakers on the vulnerability inherent in overreliance on oil exports and the urgent need to diversify the economy.
\end{abstract}

Keyword: Oil price; Econometric; Input-output; Malaysia 